\title{
3. Steering mechanisms for social and socioecological systems
}

\section{AN INTRODUCTION TO SOCIAL STEERING}

Governance is a social function centered on steering societies away from collectively undesirable outcomes and toward collectively good ones. For example, we have a shared interest in finding ways to avoid extreme depletions of renewable natural resources or severe shortfalls in the provision of clean air resulting from the impacts of collective-action dilemmas like the tragedy of the commons or the free-rider problem. Similarly, we want to achieve sustainability featuring a proper and lasting balance among economic development, sociocultural integrity, and ecological resilience. Needs for governance dealing with matters relating to socioecological systems arise at all times and at all levels of social organization. But the onset of the Anthropocene, an era featuring the emergence of human-dominated systems on a planetary scale (Vitousek et al. 1997), has brought with it a growing concern regarding the need to avoid transgressing "planetary boundaries" involving matters like climate change and the loss of biological diversity (Steffen et al. 2004; Rockström et al. 2009; Steffen et al. 2018). A critical challenge coming into focus today is to provide a "safe operating space for humanity" in a setting characterized by high levels of uncertainty arising from the dynamics of complex systems featuring extensive telecouplings, nonlinear dynamics, and critical transitions (Rockström et al. 2009; Scheffer 2009; Scheffer et al. 2009; Young 2017).

Governance systems established to address needs for governance are social institutions, developing spontaneously, as in the case of many traditional systems guiding human uses of local commons (Ostrom 1990), or resulting from deliberate actions, as in the case of regimes articulated in legislative acts or international agreements (Young 1999). Every society develops institutions of this sort to perform the function of governance. Like all social institutions, the resultant governance systems are dynamic. They arise, adapt to changing circumstances, sometimes morph into significantly altered arrangements, and eventually recede into the background or give way in the face of efforts to respond to new or increasingly urgent needs for governance. 
Often, it makes sense to assign the task of creating, administering, and adjusting governance systems to changing circumstances to governments construed as organizations authorized and supported by societies to deal with the function of governance. But this is not always the case. Although needs for governance arise in all settings, some societies (e.g., many smallscale traditional societies, international society) lack a government in the ordinary sense of the term (Bull 1977; Rosenau and Czempiel 1992). Even in settings where they do exist, governments are expensive to operate, consuming societal resources that otherwise could be applied to the pursuit of other objectives. And governments are (more or less) vulnerable to corruption, ranging from the diversion of resources from their intended uses to degeneration into profoundly corrupt or increasingly authoritarian regimes. This makes it worth thinking carefully about options for meeting needs for governance that do not rely on actions on the part of a government. My intention in identifying these concerns is not to prepare the way for a libertarian critique of the important roles that governments can and often do play in meeting needs for governance (Hayek 1973). But it is always a good idea to engage in critical assessments of proposals calling for expansions in the roles assigned to governments. In situations where there is no government to play this role and proposals to create a government (e.g., the establishment of some sort of world government) are not likely to bear fruit during the foreseeable future, there is no substitute for thinking creatively about what we have come to refer to as governance without government (Rosenau and Czempiel 1992).

To make progress toward meeting needs for governance, all governance systems must put in place mechanisms to steer or guide the actions of those subject to their provisions. In Western neoliberal thinking, there is a pronounced tendency to assume that this means introducing rules in the sense of authoritative requirements and prohibitions telling subjects what they are obligated to do or not to do under specified circumstances. Often described in terms of the idea of the rules of the game, such prescriptions constitute the hallmark of rules-based governance (North 1990). Nevertheless, rules-based governance is not the only option available to those thinking about the mechanisms available to steer the behavior of a society's members or others subject to its governance systems. Even in Western settings, a range of other behavioral mechanisms arise in specific situations to steer the behavior of relevant actors.

These observations suggest a number of questions that together constitute the principal concern of this chapter. What are the distinct types of behavioral mechanisms employed in the operation of governance systems and how exactly do they differ from one another with respect to the methods they use to influence the actions of subjects? What conditions are likely to determine the effectiveness of individual mechanisms? Or, to put this question another 
way, how should we think about the fit or the match between behavioral mechanisms on the one hand and the nature of specific needs for governance, the character of the relevant actors, and the distinctive features of the broader social setting on the other? What are the major sources of the gap between the ideal and the actual in this realm, and what strategies are available for minimizing this gap in specific situations, without triggering unintended and costly side effects? Can considerations of fairness or justice make a difference regarding the performance of behavioral mechanisms used to address a variety of needs for governance? The goal of this effort to address these questions is not to determine whether some behavioral mechanisms are better than others in some general sense, much less to arrive at some conclusion regarding the best mechanism to use in thinking about ways to meet needs for governance arising in socioecological systems in today's world. What is needed instead is critical thinking about the range of mechanisms available and about the circumstances under which it makes sense to select one of these mechanisms (or some combination of them) in the effort to meet specific needs for governance.

My current applied work focuses on a class of needs for governance that are particularly difficult to address within the framework of international society treated as a society of states (Young, Yang, and Guttman 2020). Representative examples include the avoidance of disruptive climate change, the management of cyberspace, and the regulation of innovations in biotechnology including germline editing. But the issues I address in this chapter are universal. Social steering requires the operation of mechanisms to guide the behavior of relevant actors in a wide range of settings. Conclusions derived from experience with efforts to address needs for governance in any given issue area or sociocultural setting are well worth examining with care to determine whether they provide insights of interest to those concerned with meeting needs for governance arising in other issue areas or in other settings.

\section{A TYPOLOGY OF BEHAVIORAL MECHANISMS}

Our point of departure, then, is the proposition that, to be effective, all governance systems must establish mechanisms capable of inducing subjects to behave in ways that differ from how they would behave if left to their own devices. Governance systems make use of a range of differentiable mechanisms to perform this function in a variety of settings. This makes it important to seek clarity regarding the distinctive features of each of these mechanisms as well as the character of the governance systems within which they are embedded. The resultant distinctions are analytic; hybrid systems that make use of two or more distinct mechanisms are common in real-world situations. The construction of a typology, moreover, tells us nothing about those factors likely to determine the effectiveness of specific mechanisms in guiding behav- 
ior under a variety of conditions. These issues will come into focus later in the chapter. For starters, however, my objective is to develop a well-crafted typology covering the major types of behavioral mechanisms used in governance systems in a range of societal contexts. Here, I discuss rules-based governance, principles-based governance, pledge-based governance, goals-based governance, standards-based governance, and hybrid systems.

\section{Rules-Based Governance}

Rules are authoritative prescriptions telling the members of designated groups of subjects what they are obligated to do or not to do under more or less well-defined circumstances. Many analysts - particularly those schooled in Western intellectual traditions - take it for granted that rules-based governance is the norm and that the rule of law represents the gold standard in responding to needs for governance (Chayes and Chayes 1995; Zaelke et al. 2005). Rules are enacted through the operation of authoritative procedures (e.g., legislative actions in liberal democracies) and implemented by public agencies whose mission is to translate rules from paper to practice, starting with the promulgation of regulations intended to operationalize rules for application to a range of real-world situations. In the typical case, the rules are expected to remain in place indefinitely. Two distinct but interlocking types of rules are prominent in such systems: constitutive rules and operating or regulatory rules. Constitutive rules provide general "rules of the game" relating to a broad range of issues. They are articulated typically in the form of constitutions or charters (e.g., the Charter of the United Nations). Operating rules, by contrast, consist of more focused measures (requirements and prohibitions) relating to specific issues or spatially defined areas (e.g., the regime dealing with ozone-depleting substances, the regime for Antarctica). For the most part, regulatory rules operate under the auspices of relevant constitutive rules. In the case of the ozone regime, for example, we think of this governance system as a regulatory arrangement whose elements are set forth in legally binding instruments negotiated by states operating under the auspices of the United Nations.

The development of rules-based governance systems involves several distinct steps. Once agreement is reached on the content of the rules, attention turns to the processes involved in moving them from paper to practice: operationalizing the rules in the form of regulations; establishing arrangements for monitoring, reporting, and verification; setting up compliance procedures including enforcement mechanisms if necessary; and making arrangements to produce authoritative interpretations regarding the application of the rules to specific situations when disagreements about such matters arise. Governance systems composed of sets of rules evolve over time either through the adoption of amendments or through new interpretations arising in response to changing 
circumstances or shifts in relationships among members of the subject group. This makes it important to think about institutional dynamics in any effort either to understand the operation of governance systems or to evaluate their performance in addressing the needs for governance that led to their creation (Young 2010).

\section{Principles-Based Governance}

Despite its prominence in Western thinking, rules-based governance is not the only option available to those endeavoring to devise behavioral mechanisms to meet needs for governance arising in a variety of settings. Principles, in contrast to rules, are normatively grounded prescriptions indicating what subjects should or ought to do under a variety of circumstances (Young 2017). Taken together, interlocking sets of principles add up to codes of conduct or ethical systems (e.g., legal or medical ethics). Whereas rules constitute legally or politically binding obligations, principles take the form of normatively grounded codes of proper conduct. Subjects normally think in terms of the logic of consequences in deciding whether or not to comply with rules or authoritative judgments regarding applications of the rules to specific situations (March and Olsen 1998). They are more likely to be influenced by the logic of appropriateness in responding to the prescriptive implications of principles (March and Olsen 1998). Prominent international examples of principles-based governance arrangements include the Equator Principles, dealing with environmental and social risk management, and the Sullivan Principles, dealing with corporate social responsibility, particularly in situations involving racial prejudice.

Unlike rules, which are articulated in the decisions of authoritative bodies, principles normally arise and take effect through processes of socialization; they often apply to the behavior of individuals rather than the actions of states. Actors often make explicit decisions about compliance with rules, taking into account the probable consequences of noncompliance (Young 1979). By contrast, they are socialized to internalize principles, so that compliance typically takes the form of habitual behavior rather than becoming a matter of weighing the costs and benefits associated with (non)compliance on a case-by-case basis. As a result, compliance with principles is better understood as a response to social pressure rather than as a matter of enforcement. Those who think about rules-based governance commonly focus on the (prospective) use of formal sanctions as a means of enforcing compliance with rules; those who focus on principles-based governance pay more attention to normative mechanisms like naming and shaming as a means of guiding the behavior of subjects. Violators of principles are subject to ethical condemnation on the part of others; violators of rules are subject to enforcement actions on the part of designated authorities. 


\section{Pledge-Based Governance}

Pledges are voluntary commitments that subjects of governance systems (e.g., regime members and other key actors) make regarding their contributions to the achievement of collectively defined objectives. Superficially, the power of pledges may seem limited by comparison with the power of legally or politically binding rules or the effects of normatively grounded principles, especially in settings where the bonds of community membership are not strong. Yet it would be a mistake to underestimate the behavioral consequences of pledges under a variety of circumstances. Consider the role of tithing in religious settings or the pledges that philanthropists make in support of good causes as examples of the behavioral significance of pledges. As the history of charitable giving makes clear, there are even cases in which those in possession of wealth compete with regard to the generosity of their contributions to worthy causes. In concrete situations, pledges are likely to vary both in kind and in size depending upon the circumstances of individual actors. A prominent case in point involves the Nationally Determined Contributions (NDCs) made by states that have subscribed to the provisions of the 2015 Paris Climate Agreement. Whereas developed states are expected to make pledges regarding quantified reductions in their aggregate emissions of greenhouse gases, developing states are more likely to make pledges emphasizing reductions in the energy intensity of major industries.

A common feature of pledge-based governance is the use of "pledge and review" procedures as a means of steering behavior toward desired ends. The Paris Climate Agreement, for example, includes a provision calling for a periodic "global stocktake" intended to operate as a means of ratcheting up the pledges of members over time (Paris Climate Agreement 2015). Members are expected to participate in a systematic review process conducted at five-year intervals in order to assess progress toward meeting common objectives regarding efforts to address the problem of climate change. The results of the review process should provide incentives for individual members to strengthen or ratchet up their NDCs during the next commitment period. Over time, the objective is to launch a stepwise progression toward solving the common problem of climate change. There is nothing automatic about such processes; they may fail to generate timely progress toward meeting needs for governance in specific situations. Still, pledge-based governance may set in motion movement in the right direction in situations where the scale of commitments needed to solve a problem is not known or pledges of the required magnitude are not feasible at the outset. 


\section{Goals-Based Governance}

Goals are collectively determined priority objectives to be pursued as a matter of urgency during a specified period of time. As a steering mechanism, this governance strategy involves setting priorities, allocating resources to the pursuit of priority goals, assigning personnel, launching campaigns to galvanize action, and monitoring progress with an eye toward redoubling efforts if needed to make progress in a timely manner (Kanie and Biermann 2017). A classic case in point is the American Apollo Project launched at the beginning of the Kennedy Administration to put a man on the moon by the end of the decade of the 1960s. Prominent international examples include the objective of Millennium Development Goal No. 1 calling for a campaign to halve the number of people living on less than $\$ 1.25$ a day by 2015 and the campaign spearheaded by the World Health Organization during the 1970s-1980s to eradicate smallpox (Sachs 2015; Cueto et al. 2019). Whereas rules are normally meant to remain in place indefinitely, goals are intended to galvanize concerted efforts to meet targets during a specific time period, with the expectation that subsequent time periods will highlight new goals.

In some respects, goals-based governance constitutes an alternative to the general Western preference for the rule of law. Rules-based governance features binding prescriptions operationalized in the form of regulations that are expected to remain in place indefinitely and that are enforceable through the operation of a legal system. Governing through goals, by contrast, involves the concentration of societal resources to galvanize action toward the achievement of collectively determined objectives. This suggests that the choice between rules-based and goals-based steering mechanisms is likely to be related to underlying differences in societal structures or cultural preferences (Zhao et al. 2020). In systems featuring a clear separation between the private sector and the public sector, private actors are likely to control the lion's share of society's material resources. The role of the public sector is to regulate the behavior of private actors in the interests of avoiding collectively undesirable outcomes and achieving desirable ones. Systems featuring central planning (e.g., through the development and implementation of five-year plans), on the other hand, are not marked by such a clear separation between the public sector and the private sector. In such systems, central authorities are able to make overall decisions regarding the allocation of society's resources, a situation that lends itself to setting societal priorities and mobilizing the resources needed to pursue them collectively. 


\section{Standards-Based Governance}

Standards are performance criteria that actors must meet in order to qualify for some privilege or to receive some beneficial certification. The use of standards as a behavioral mechanism is common in a variety of settings. For example, students are expected to demonstrate a certain measure of proficiency at lower levels before being allowed to enroll in higher-level courses of instruction. Those desiring to receive certification regarding green building standards (e.g., LEED silver, gold, or platinum certification) must show proof of conformance with well-defined standards. Similar arrangements are becoming increasingly common at higher levels of social organization. The Forest Stewardship Council and the Marine Stewardship Council operate certification systems dealing with sustainable harvesting practices; the International Organization for Standardization (ISO) provides standards in a number of areas (e.g., ISO 26000, which sets forth standards for businesses and organizations desiring to operate in a socially responsible way). More often than not, standards are intended to guide the actions of private actors, though there are cases in which national authorities adopt standards promulgated by organizations like ISO and proceed to apply them to those operating under their jurisdiction.

Given the voluntary nature of many standards, why do corporations and other actors accept them and make a concerted effort to live up to the relevant requirements (van der Ven 2019)? Part of the answer to this question undoubtedly lies in the logic of appropriateness. Owners of LEED-certified buildings may act, at least in part, out of a general commitment to norms of environmental sustainability. But in many cases, there are perfectly good reasons for adhering to standards rooted in the logic of consequences. Corporations, for example, may benefit from branding their products as sustainable or acquiring a reputation for adhering to high standards of corporate social responsibility. Others may value the credibility in the eyes of important constituencies expected to result from visible commitments to high standards in relevant areas. In all cases, standards-based governance raises issues of monitoring and periodic recertification. Although there are cases in which certification is a one-shot proposition (e.g., standards regarding the use of certain building materials), most situations involve a need to demonstrate continued conformance to the relevant requirements over time. Whether the issue is green building standards or sustainable harvesting practices, a critical issue involves the extent to which actors adhere to commitments to maintain high standards following initial certification. Typically, recertification practices are just as important to the performance of standards-based governance as the procedures governing initial certification. 


\section{Hybrid Systems}

As I noted at the beginning of this section, these are analytic distinctions. They are useful in understanding key differences among the behavioral mechanisms used in a variety of social settings to steer or guide the behavior of relevant actors in efforts to meet needs for governance. Although some governance systems rely exclusively on a single behavioral mechanism, hybrid systems are common. Consider the case of the 2015 Paris Climate Agreement for illustrative purposes (Paris Climate Agreement 2015). This agreement articulates a well-defined goal. Specifically, it seeks to operationalize the rather vague commitment set forth in Article 2 of the UN Framework Convention on Climate Change by setting a goal of limiting temperature increases at the Earth's surface to $2^{\circ} \mathrm{C}$ above pre-industrial levels and striving to limit these increases to $1.5^{\circ} \mathrm{C}$. It then proceeds to adopt a pledge-and-review procedure governing efforts to fulfill this goal. As noted previously, this procedure takes the form of the submission of NDCs on the part of member states coupled with the Global Stocktake process designed to ratchet up the strength of pledges over time. At the same time, the agreement highlights certain normatively grounded principles intended to guide the actions of members of the regime. A particularly prominent example is the principle of common but differentiated responsibilities introduced to separate developed countries and developing countries with regard to the nature of their obligations to contribute to meeting the common goal. Nor is the agreement lacking in rules. There are, for example, well-defined requirements relating to monitoring, reporting, and verification, which are seen as essential to the performance of the regime in meeting the relevant need for governance over time. Of course, none of this offers any guarantee that the Paris Climate Agreement will prove effective in solving the problem of climate change. At this writing, the evidence is not particularly encouraging. Nevertheless, this regime does provide a clear example of the common practice of joining two or more behavioral mechanisms together in efforts to address complex needs for governance such as the problem of addressing climate change.

\section{Alternative Perspectives}

This account of behavioral mechanisms expands the scope of mainstream thinking about governance considerably. But I do not claim that the typology I have presented is exhaustive. For one thing, it is probably fair to suggest that the forms of governance I have discussed all derive in some general sense from Western experiences and Western perspectives on ways to address the social function of governance. Governance is a social function centered on societal steering, and steering requires finding ways to guide the behavior of relevant 
actors. This much seems universal. Still, there may be distinctive modes of thought regarding ways to perform this function grounded in non-Western experiences. It seems to me particularly important at this juncture to consider Chinese perspectives on governance, both because China has become a leading player on the global scene and because China's leaders, including President $\mathrm{Xi}$, regularly make use of the idea of governance in discussing China's role in the world (Young, Yang, and Guttman 2020). The cultural and historical roots of Chinese thinking about governance go deep, including Confucian thinking about steering through education. But there is as yet no fully articulated modern discussion of the major sources of Chinese thinking in this area, much less sophisticated accounts of the application of the relevant ideas to contemporary needs for governance. Among the most interesting prospects in this realm that have come to my attention are the ideas associated with what Chinese thinkers describe as tianxia theory and gongsheng/symbiotic theory (Zhao 2019; Ren no date).

\section{DETERMINANTS OF EFFECTIVENESS: THE PROBLEM OF FIT}

There is nothing to be gained from seeking to weigh the merits of these behavioral mechanisms in an effort to determine whether one or another of them is to be preferred in some general or overall sense. Taken together, the collection of mechanisms discussed in the preceding section can be treated as a toolkit containing a range of options that will prove more or less helpful in addressing particular needs for governance. Approached in this way, the relevant question becomes: What mechanism or combination of mechanisms will produce the best results in specific situations? We can think about the resultant problem of fit from (at least) three distinct perspectives. Are specific behavioral mechanisms more or less well suited to addressing various types of problems? Are particular mechanisms likely to work better in guiding the behavior of some types of actors in contrast to others? To what extent are the different mechanisms compatible with the broader social settings within which they operate? To respond to these questions in a comprehensive manner will require extensive research. In this section, my purpose is simply to provide some initial thoughts intended to seed a more systematic treatment of the issue.

\section{Fit 1 - Problem Types}

Not all problems giving rise to needs for governance are alike. As a result, it makes sense to eschew panaceas, examining the defining characteristics of problems case-by-case in search of insights relevant to the selection of behavioral mechanisms likely to prove effective in achieving socially desirable 
outcomes (Young, Webster et al. 2018). Consider the following examples as illustrations of this proposition. It is possible to solve some problems once and for all (e.g., the eradication of smallpox), whereas other problems (e.g., the control of nuclear weapons) require attention on an ongoing basis. Goals-based governance may provide an effective and efficient strategy for addressing problems like the eradication of smallpox. But rules-based governance makes more sense in a case like the control of nuclear weapons, where there are good reasons to believe that the challenge will remain a prominent concern over time. In some cases, the choice of behavioral mechanisms may be sensitive to the way we choose to frame a need for governance. If we approach the problem of climate change as a matter of transforming economies to eliminate or drastically reduce the use of fossil fuels, for instance, it makes sense to think of the challenge as a matter of pursuing the goal of economic transformation. If we take the view that some form of geoengineering will be necessary to meet the challenge of climate change, on the other hand, there will be a need to devise a regulatory regime imposing requirements and prohibitions on the practice of geoengineering over the long run.

Collective-action problems (e.g., the control of ozone-depleting substances) differ from problems featuring externalities (e.g., long-range air pollution, marine dead zones) in ways that have important implications for the selection of behavioral mechanisms. Whereas actors involved in collective-action problems have (more or less strong) incentives to cooperate on their own, those whose actions produce externalities have little incentive to alter their behavior in the absence of intervention on the part of society. This suggests that pledge-based governance coupled with reassurance procedures may work in a case like controlling emissions of greenhouse gases where individual subjects are willing to make good on their pledges so long as they are confident that other members of the group are able and willing to do the same. But it is hard to avoid the conclusion that regulatory measures will be needed to steer the behavior of those who are sources of externalities, unless and until they make fundamental changes in the activities that cause the problem (e.g., switching to energy sources that do not generate emissions of greenhouse gases).

Some problems are more volatile than others in the sense that they involve complex systems subject to nonlinear and often surprising changes. In dealing with volatile systems, there is a need to avoid lock-in so that it is possible to adapt governance systems relatively easily and quickly to changing circumstances (Young 2017). This is apt to present a (more or less) serious problem in the context of rules-based systems, especially where altering or even amending the rules is likely to involve contentious processes and may fall victim to gridlock. On the other hand, since rules-based systems may have advantages arising from the willingness of subjects to comply with requirements and 
prohibitions they accept as legitimate, there will often be a tradeoff between the advantages of rules-based governance and the virtues of other behavioral mechanisms featuring pledges or standards. Achieving an optimal balance between the two may prove difficult. But especially in today's setting, which features increasingly complex and volatile systems, there are good reasons to recognize the importance of this tradeoff and to make a concerted effort to achieve a suitable balance on a case-by-case basis.

What these examples have in common is a concern for matching the character of the behavioral mechanism(s) employed to the key features of the problem to be solved (Galaz et al. 2008). Obviously, such examples are merely illustrative of a major challenge confronting those interested in meeting needs for governance in a wide range of settings. Addressing the problem of fit does not lend itself to the conduct of routinized analysis, especially as we find ourselves dealing with increasingly complex systems. To meet this challenge, we need critical thinking both about the intrinsic character of different needs for governance and about alternative ways to frame specific problems that have important implications for the choice of mechanisms to steer the behavior of key actors in specific settings.

\section{Fit 2 - Types of Actors}

Just as not all problems are alike when it comes to matters of steering, there are also variations among types of actors that have significant implications for the operation of behavioral mechanisms. Consider the following examples as illustrations of this proposition. Whereas many conventional models start from the assumption that all actors are rational and self-interested utility maximizers who employ some sort of benefit-cost calculations in making choices, the contributions of behavioral economics over the last several decades have revealed the limits of this assumption (Kahneman 2011; Thaler 2015). We now know, for instance, that some actors are absolute gains maximizers while others are concerned with relative gains, that actors have different discount rates in thinking about the future consequences of the choices they make today, that actors vary in terms of their sensitivity to the logic of appropriateness in contrast to the logic of consequences, and that some actors are more concerned than others about the impacts of their actions on the welfare of others. The implications of these and other similar findings regarding the operation of behavioral mechanisms are far-reaching. Principles-based governance may work well among actors sensitive to the logic of appropriateness. Actors with low discount rates are likely to be more receptive to pledge-based governance dealing with long-term concerns like climate change than those with high discount rates who care little about longer-term consequences. Steering the behavior of relative gains maximizers, on the other hand, is apt to require 
rules-based governance systems backed by well-developed compliance procedures including a capacity to make use of meaningful sanctions. Clearly, the range of variation in this realm is broad; the use of simplistic assumptions in the interests of achieving analytic tractability is not likely to help in meeting real needs for governance.

There is an important distinction in this context between actors that are collective entities versus those that are individuals. To be sure, individuals may experience more or less severe inner conflict regarding their behavior in situations featuring needs for governance. There is nothing surprising, for example, about cases in which individuals are torn between normative pressure to abide by ethical principles and a self-interested desire to take advantage of opportunities to maximize material rewards accruing to themselves. Nevertheless, there is an important difference between individuals and collective entities (e.g., states, corporations) whose behavior is subject to the logic of two-level games (Putnam 1988). The external behavior of collective entities is subject to internal bargaining processes involving interest groups whose motivations and preferences may vary dramatically. From the perspective of governance, this suggests the value of making use of two or more behavioral mechanisms at the same time. While principles-based or standards-based governance may attract the support of some factions in the internal bargaining processes of subjects, for instance, others may be more responsive to rules-based governance calling attention explicitly to procedures emphasizing matters of compliance and enforcement.

There are as well cases in which the group of subjects whose actions are relevant to a need for governance includes individual members that differ greatly from one another regarding the sources of their behavior. A prominent case in point arising in efforts to address problems like climate change involves the distinction between liberal democracies characterized by a clear separation between the public sector and the private sector and centrally planned systems featuring some form of top-down or authoritarian decision-making (Young et al. 2015). It is difficult to devise rules-based arrangements that work equally well in steering the behavior of both types of actors. In such cases, a combination of rules-based and goals-based governance may prove attractive. The essential feature of such arrangements, exemplified by the Paris Climate Agreement, is the articulation of a common goal coupled with an arrangement allowing individual subjects to make pledges reflecting the distinctive features of their own internal systems. As in the case of problem types, the message here is straightforward. Addressing the problem of fit requires a willingness to devise behavioral mechanisms whose defining features are well matched to the character of the actors involved. 


\section{Fit 3 - The Broader Setting}

What is more, governance systems are sensitive to the character of the broader settings within which they operate. Most governance systems are specific arrangements developed, whether spontaneously or intentionally, to address particular needs for governance. But they operate within broader socioeconomic and political settings that affect their ability to steer or guide behavior effectively. This suggests the importance of thinking about the design of behavioral mechanisms for use in specific cases with an eye toward achieving compatibility with the established practices of the setting in which they will operate. Whereas a governance system that fits comfortably within the ambit of a society's normal or conventional practices may experience relatively smooth sailing, a system that departs in important ways from mainstream practices may run into trouble before it gets off the ground.

In some cases, issue-specific governance systems can take advantage of the existence of overarching arrangements to avoid the need to address some functions on a case-by-case basis. Consider arrangements dealing with matters of compliance and authoritative interpretation as cases in point. Where societies have properly functioning enforcement agencies and legitimate judicial institutions, issue-specific systems may be able to make use of these arrangements to deal with matters of compliance and dispute settlement, avoiding the need to create costly and potentially controversial arrangements of their own. Similar observations are in order regarding procedures for adjusting the provisions of issue-specific governance systems to meet changing conditions. Nevertheless, some words of caution are in order regarding the advantages of ensuring compatibility with overarching social practices. In some cases, established practices may be part of the problem rather than part of the solution. There is a legitimate question, for example, whether Western practices grounded in what analysts think of as the rule of law are capable of introducing the transformative measures needed to come to terms with a problem like climate change.

It is also worth noting that the social practices we associate with the broader setting may be subject to change themselves. While some see international society as an unchanging anarchical system of sovereign states seeking to maximize relative gains in the absence of anything like a government, others take the view that this system is experiencing significant change regarding both the character of its members and the defining features of its social practices (Bull 1977; Hurrell 2007; Zürn 2018). In a setting of this sort, issue-specific governance systems may become agents of change in contrast to subordinate arrangements that must conform to established societal practices in order to become effective. To return to the case of climate change, the actions required to come to grips with this problem may well call for significant adjustments in 
the character of international society. As the history of efforts to address the problem of climate change makes clear, such adjustments do not come easily. Nonetheless, when this problem precipitates a severe systemic crisis, there may be no other way to solve it.

\section{CAN CONSIDERATIONS OF FAIRNESS OR JUSTICE MAKE A DIFFERENCE?}

There is a growing interest in discussions of governance in considerations of fairness or justice. What should we make of this development with regard to the concerns of this chapter? Many of the resultant contributions focus on issues of substantive justice. Do behavioral mechanisms treat the rights and interests of (groups of) subjects fairly? Do outcomes flowing from the operation of governance systems accord with relevant criteria of distributive justice? Clearly, these are important questions. But it is equally clear that they are difficult to answer persuasively in many - perhaps most - real-world settings. Part of the problem lies in disagreements regarding the appropriate standards of fairness to employ in evaluating the performance of the behavioral mechanisms involved in efforts to deal with specific needs for governance. Those looking at the same governance system from different vantage points can and often do arrive at fundamentally different conclusions regarding the fairness of the outcomes. A striking contemporary example involves proposed solutions to the problem of climate change, which many Americans regard as unfair to the United States, while most others see them as unfair to themselves. Another part of the problem arises from difficulties in establishing clear causal connections between the operation of governance systems and outcomes evaluated from the perspective of fairness or justice. As those struggling to assess the performance of international regimes know well, establishing causality in this realm is difficult both because multiple drivers play more or less significant roles in specific situations and because what is often described as conjunctural causation makes it hard to attach specific weights to the importance of governance systems (Ragin 1987; Young 2011). As a result, debates about the extent to which the operation of specific institutions yields outcomes that are fair or just in distributive terms often degenerate into acrimonious and inconclusive arguments.

There is another perspective on issues of fairness or justice that may prove more helpful in thinking about the performance of the behavioral mechanisms governance systems use to guide behavior in a variety of settings. This perspective focuses on what is typically called procedural fairness or justice; it asks whether there are links between the extent to which subjects regard the operation of a behavioral mechanism as fair in procedural terms on the one hand and the effectiveness of the mechanism in steering behavior in the desired 
direction on the other. This line of thinking rests on a sizable body of research demonstrating that actors of various types are willing to accept outcomes they feel have been arrived at through the use of fair procedures that they would be unwilling to accept when they regard them as emanating from processes they see as unfair or unjust (Gupta and Mason 2014). Often, these links are hard to account for in terms of mainstream models that treat actors as self-interested utility maximizers. But to the extent that this is the case, it is testimony to the inadequacy of the models rather than to the irrationality or uninformed behavior of the relevant actors.

These observations suggest the value of conducting systematic research on the links between the performance of behavioral mechanisms and the role of procedural justice. We might begin by asking whether a sense of procedural justice is either necessary or sufficient for the behavioral mechanisms used in governance systems to achieve success in steering or guiding the behavior of relevant subjects. While there is an obvious need for systematic analysis regarding this question, it seems unlikely that such research will yield an affirmative response to the question. There is little doubt that some behavioral mechanisms will fail to produce the desired results, even when subjects generally regard them as fair or just in procedural terms. Conversely, it would be difficult to make a persuasive case for the proposition that behavioral mechanisms can never achieve success in steering or guiding behavior in the absence of feelings on the part of subjects that they meet relevant standards of procedural fairness or justice.

Still, this leaves ample room for additional analysis regarding links that make a difference, though they do not qualify as necessary or sufficient conditions. What seems important in behavioral terms is the extent to which subjects themselves regard mechanisms as fair or just in procedural terms, rather than the extent to which the mechanisms conform to standards lodged in the minds of outside observers. This suggests the importance of asking about conditions that are likely to determine whether subjects feel behavioral mechanisms are fair or just in procedural terms. Can we develop broad generalizations in response to this question? Are feelings of procedural fairness or justice likely to be situation-specific? Are the same mechanisms that some see as operating in a fair or just manner likely to be dismissed as unfair or unjust by others? In principle, at least, these questions fall within the scope of topics suitable for systematic research. The development of well-grounded answers, even if they confirm the supposition that feelings of fairness or justice are situation-specific, would be of great interest to those who are concerned with the challenge of meeting needs for governance arising in the Anthropocene. 

ACTUAL

What is commonly described as the gap between the ideal and the actual arises with regard to all social institutions, including governance systems. The way a governance system works in practice will diverge to a greater or lesser degree from the way it works in principle or on paper. We are used to considering this phenomenon in the case of rules-based governance where it is normal to contrast the rules in use with the rules on paper (Ostrom 1990). But similar observations are in order regarding all the behavioral mechanisms considered in this chapter. It is seldom, if ever, possible to close the gap between the ideal and the actual completely. But in most cases, there are opportunities to narrow the gap. A first step in dealing with this concern is to understand both the sources of the gap and the likely effects of the gap on the operation of specific governance systems. This can provide a point of departure for thinking about strategies for closing the gap. Here, I illustrate these observations with reference to the cases of rules-based and goals-based governance.

What are the sources of governance failure in the case of rules-based governance? Efforts to enact rules in legislative settings or to reach agreement on the provisions of international agreements may fail, ending in gridlock or stalemate. Even when they do succeed, the compromises needed to reach agreement may make the results incoherent or give rise to formulations that are framed in such vague or ambiguous terms that it is difficult to make sense of them when it comes to making the transition from paper to practice. There is as well a range of concerns relating to the implementation of rules-based governance systems and the occurrence of unintended consequences arising from the application of such systems to specific cases. These concerns range from the deadening effects of bureaucratic red tape to the occurrence of endless legal battles and on to the problems associated with economic and political corruption. There are many cases in which compliance procedures and enforcement mechanisms fail to develop or remain underdeveloped so that actual behavior bears little resemblance to expectations associated with the rules in use, much less the rules on paper. There is nothing inevitable about the occurrence of any of these problems. Taken together, however, they present serious challenges that those seeking to create effective rules-based governance systems neglect at their peril. This means efforts to reduce the gap between the ideal and the actual must constitute a constant concern for those committed to using the promulgation and application of rules as a means of steering behavior in a wide range of settings.

Similar remarks are relevant in the case of goals-based governance. Efforts to set priorities often bog down or produce ambiguous results, especially in set- 
tings where numerous influential stakeholders pursue disparate goals (Kanie and Biermann 2017). As the case of the UN's Sustainable Development Goals makes clear, a common outcome of efforts to set priorities is the inclusion of so many distinct elements that the results are hard to differentiate from situations in which there are no clear priorities. Goals-based governance also may suffer from the provision of inadequate resources, the absence of effective leadership, and the lack of well-defined and easily understood indicators to assess progress toward the fulfillment of the goals along the way. Nor is goals-based governance immune from conventional forms of corruption featuring favoritism in the assignment of tasks or the siphoning off of public resources to promote private purposes. Here, too, the opening up of these gaps between the ideal and the actual is not inevitable. But falling prey to one or more of these perils is always a possibility, and those desiring to govern through goals effectively must be alert to these concerns during all phases of the governance process.

Any effort to evaluate the effectiveness of a behavioral mechanism or the performance of the governance system of which it is a part must take the actual rather than the ideal as a point of departure. Still, this does not rule out initiatives aimed at reducing the gap between the ideal and the actual in specific situations. There are no simple recipes for closing this gap. But there are strategies for minimizing the gap that may prove (more or less) effective in specific situations. It is important to pay close attention to creating governance systems that are well suited to addressing specific needs for governance. A good match between the problem at hand and the governance system created to address it provides no guarantee regarding efforts to minimize the gap between the ideal and the actual. But a bad match increases substantially the probability of a sizable gap arising. It is important as well to maintain vigilance in this realm, tracking progress closely and building in procedures for making mid-course corrections to minimize the gap between the ideal and the actual while governance systems are in operation. While there is no simple formula for dealing with this challenge, a variety of procedures are worth considering, including the launching of pilot projects, legislative oversight, government accounting procedures, and the use of the courts both to bring pressure to bear on administrators to implement the provisions of governance systems faithfully and to sanction those who abuse their authority in such settings or engage in corrupt practices.

An important concern in thinking about strategies for reducing this gap centers on the danger of generating unintended and often unforeseen side effects in the course of endeavoring to minimize the gap between the ideal and the actual. Perhaps the most obvious danger arises from the impacts of authoritarian procedures designed to force agreement on priorities, to cut through red tape, to galvanize campaigns to fulfill goals, to deter various forms of corruption, and so forth (Zhao et al. 2020). The problem here is that proce- 
dures introduced in the interests of maximizing the effectiveness of behavioral mechanisms may produce side effects in terms of the loss of capacity to innovate or the infringement of civil liberties that are just as costly to society as a failure to deal effectively with some specific needs for governance. Efforts to close the gap between the ideal and the actual with regard to specific needs for governance may trigger the development of a higher-order gap between the ideal and the actual regarding overarching societal values. There is no simple recipe for avoiding this danger. But fostering awareness of the problem is certainly a necessary step for those seeking to avoid falling into this trap.

\section{A CONCLUDING OBSERVATION}

Readers may interpret the argument of this chapter either in positive terms or in normative terms. In positive terms, the central objective is to clarify differences among types of governance systems, to identify conditions under which governance systems are likely to rely on one behavioral mechanism or another, and to offer some insights regarding the effectiveness of governance systems operating in real-world settings. From a normative perspective, on the other hand, the principal objective is to provide insights that may prove helpful to those responsible for devising governance systems to meet specific needs for governance and for operating these systems under real-world conditions. In both cases, the analysis raises more questions for further consideration than it is able to answer in a compelling fashion. We know some things that are relevant to meeting the challenge of steering toward sustainability. But we need to know much more about this subject, especially as we endeavor to put in place behavioral mechanisms and, more broadly, governance systems capable of addressing urgent needs for governance arising in the Anthropocene. 